\title{
Research on Tourism Destination Development and Countermeasures of Hainan Island Without Residents Against the Background of Free Trade Zone Construction
}

\author{
—Taking Jiajing Island as an Example
}

\author{
Kun Zhang \\ College of Tourism \\ Hainan Tropical Ocean University \\ Sanya, Hainan, 572022, China \\ e-mail: kunzhang@ hntou.edu.cn
}

Haifeng Wang

College of Computer Science and Technology

Hainan Tropical Ocean University

Sanya, Hainan, 572022, China

\author{
Jia Zhu* \\ College of Art \\ Hainan Tropical Ocean University \\ Sanya, China, 572022, China \\ * Corresponding author e-mail: zhujia1217@126.com
}

\author{
Wentao Zhang \\ Education Center of MTA, College of Tourism \\ Hainan Tropical Ocean University \\ Sanya, China, 572022, China
}

\begin{abstract}
The concept of sustainable development in the development of tourism is sustainable tourism. The World Tourism Organization believes that sustainable tourism is "to maintain the cultural integrity and the ecological environment while meeting people's economic, social, and aesthetic requirements; it can provide livelihoods for today's hosts and guests, while protecting and enhancing future generations. Benefits and provide them with the same opportunities ". Based on the perspective of sustainable development, the article mainly proposes a strategy analysis of recreational development of Jiajing Island from the three aspects of ecological, economic and social coordinated development.
\end{abstract}

Keywords-Uninhabited Islands; Island Tourism; Sustainable Development

\section{DEVELOPMENT STRATEGY BASED ON ECOLOGICAL SUSTAINABILITY}

\section{A. Based on Ecological Protection}

The overall land area of Jiajing Island is small and the ecological sensitivity is relatively high. If the local ecological environment is damaged, it will have a serious impact on the overall ecological environment of Jiajing Island. Therefore, only by strictly protecting the ecological environment of Jiajing Island can the ecological sustainable development of Jiajing Island be guaranteed. Taking ecological protection as the guide is the basic requirement for the recreational development of Jiajing Island [1-2].

\section{1) For protection priority}

In the process of recreational development, the ecological environment carrying capacity of Jiajing Island must be fully considered, and the ecological environment of Jiajing Island is relatively fragile. In the process of recreational development, strict protection must be carried out. Carry out under the premise of affordability. Coordinate the relationship between Jiajing Island's ecological protection and industrial development. Priority must be given to conservation. Jiajing Island can ensure the sustainable development of Jiajing Island ecosystem only if it can achieve an ecological cycle and achieve balanced development of ecology, society, and economy [3-4].

\section{2) Moderate development}

Ecotourism resources are the foundation of sustainable development of island tourism. In the development of island recreation in Jiajing Island, the ecological resources of Jiajing Island must be developed, but the development of ecological resources will lead to the risk of damage to the island's ecological environment [5]. This contradiction is inevitable. Therefore, in the process of recreation development, it is necessary to reasonably evaluate the self-conditions of Jiajing Island and the needs of recreational development of Jiajing Island, and reasonable planning to minimize the impact of recreational development activities of Jiajing Island on the ecological environment to a minimum. We must not be blindsighted, we must ensure the healthy and sustainable operation of the ecological environment of Jiajing Island, and prevent the occurrence of behaviors that destroy the ecological environment of Jiajing Island in order to pursue short-term economic benefits [6]. 


\section{B. Delineate Ecological Protection Area}

1) Standards for delineating ecological protection areas The "Country-level (city-level) Uninhabited Island Protection and Utilization Plan Compilation Outline" requires that the area of the island protection area should be higher than or equal to one-third of the total area of the island, that is, the total projection of the single island protection area The total area cannot be less than one third of the entire island area. Secondly, the types of island protection objects are generally: rare animals and plants, vegetation with important ecological functions, animals and plants with important research and ecological value; typical ecosystems such as seagrass beds and coral reefs; special topography and geological landscape; conservation areas, Important beaches and fresh water sources; historical and cultural relics; navigational aids, surveys, place names and other public welfare facilities; military facilities, territorial sea base point protection area signs, territorial sea base point mark and azimuth, etc.; other objects with protection value [7-8].

2) The delineation of Jiajing Island ecological protection area

The degree of protection of the ecological environment will directly affect the sustainability of Jiajing Island's recreational development. The northwestern part of Jiajing Island is covered with dense tropical evergreen semi-deciduous monsoon forests, which is important for maintaining the island's natural ecology and constructing vegetation landscapes. The west part of the island has a sandy beach about $250 \mathrm{~m}$ long. For small islands with leisure and recreation as the main function, the sandy beach is an extremely important resource, and the beach also has seasonal changes; the sea area on the northwest side of the island has A large number of corals constitute a beautiful underwater coral landscape. At the same time, coral reefs are a barrier against wind and waves and protect islands [9-11]. They are an important part of island ecology. Through field investigations, it is found that seabirds inhabit the bedrock coast on the south side of the island. For breeding, there are two freshwater spring eyes on the north side of the island, and there are island name signs and geomagnetic survey azimuth points on the northwest and southwest sides. These are important resources of the island and should be actively protected [12]. Refer to Figure 1 for the delineation of the protection area of Jiajing Island.
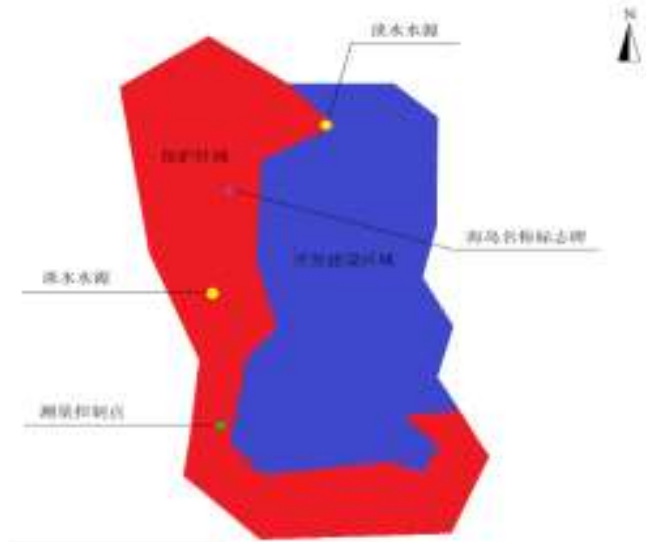

Fig. 1. Jiajing Island Protected Area Planning

\section{Red Line for Measuring Ecological Carrying Capacity}

Ecological carrying capacity is an important cornerstone supported by theoretical data in the recreational development of Jiajing Island. Determining the ecological carrying capacity of the island is a prerequisite for scientific planning and rational development of the island, and it is also an insurmountable red line in the process of recreational development. Therefore, the determination of ecological carrying capacity is an important basis for ensuring the sustainability of recreational development of Jiajing Island, and for the ecological protection of Jiajing Island. It occupies the most important position in each development link. First of all, the area of Jiajing Island is not large, there is not enough space for development and expansion, and large-scale, full-chain, multi-functional recreational development cannot be carried out. Secondly, Jiajing Island is rich in natural resources, diverse animals and plants. Therefore, when carrying out recreational development, it is necessary to measure the ecological carrying capacity of Jiajing Island and set the red line of Jiajing Island ecological carrying capacity. No matter the development process or the control of the number of tourists after operation, the ecological carrying capacity red line cannot be touched. Put an end to the phenomenon of overexploitation and use, and avoid serious damage to the ecosystem and ecosystem of Jiajing Island, resulting in the unsustainable ecology of Jiajing Island [13].

1) Currently, the widely used formula for calculating ecological carrying capacity is:

\section{$V=i M / P$}

Among them, $i$ represents the number of single-day receptions of the island, $M$ represents the area of the island available for recreational activities, $P$ represents the area per capita of tourists, and $V$ represents the ecological carrying capacity of the island that needs to be calculated. For the protection of the ecological environment, generally $P$ takes $5 \mathrm{~m}^{2} /$ person, $i$ takes 3 , and $M$ is $113901 \mathrm{~m}^{2}$ for the development and construction area of Jiajing Island. It can be calculated that the single-day carrying capacity of Jiajing Island is 68,000 person-times. If the time for island rest and self-repair is set aside for 300 days a year, then the annual ecological carrying capacity of Jiajing Island is 20.4 million person-times. Wuzhizhou Island received about 3 million people in 2018, obviously this calculation is unreasonable.

\section{2) Another calculation method}

Another calculation method is, to adopt corresponding ecological carrying capacity standards according to different types of land used in recreational areas. However, at present there is no definition of uninhabited islands. Therefore, this study refers to the "Recreation Land Ecological Capacity" in the "Specifications for Scenic Spots Planning" and calculates the ecological carrying capacity of Jiajing Island according to different standards. The calculation results are as follows: 
TABLE I. PREDICTION OF RECREATIONAL ECOLOGICAL CARRYING CAPACITY OF JIAJING ISLAND

\begin{tabular}{|c|c|c|c|}
\hline Partition type & $\begin{array}{c}\text { Area } \\
\text { (hectare) }\end{array}$ & $\begin{array}{c}\text { Reference value of } \\
\text { bearing capacity }\end{array}$ & $\begin{array}{c}\text { Single } \\
\text { bearing } \\
\text { capacity }\end{array}$ \\
\hline $\begin{array}{c}\text { Protected } \\
\text { area }\end{array}$ & 4.9531 & 4 person / ha & 20 \\
\hline $\begin{array}{c}\text { Development } \\
\text { and } \\
\text { construction } \\
\text { area }\end{array}$ & 11.3901 & 20 person / ha & 228 \\
\hline Total & 16.3431 & & 248 \\
\hline
\end{tabular}

As shown in Table I above, Jiajing Island's single tourism carrying capacity is 248 people. Assuming that the number of receptions per day is 3 , and the annual operating pick-up time is 300 days, then Jiajing Island's annual ecological carrying capacity is 223,200 . Compared with Wuzhizhou Island, the area of Jiajing Island is only about $1 / 12$ of Wuzhizhou Island. According to the current tour volume of Wuzhizhou Island, the flow rate of Jiajing Island is 250,000 , although there is a slight deviation from the measured value. But it can be seen that the calculation method is close to reality.

It can be seen from the results of the above two calculation methods: the above two calculation results can only be used as a simple reference. If recreational development is to be carried out, the eco-tourism carrying capacity of Jiajing Island needs more scientific calculations. After collecting basic data on the site of Jiajing Island, through the evaluation and calculation of experts from various departments such as the Ministry of Land, Maritime Affairs and Tourism, it is finally possible to obtain reliable ecological carrying capacity data that can be used as the parameter basis for recreational development of Jiajing Island [14-16]. As a measurement value in Jiajing Island's recreational development strategy, ecological carrying capacity does not only exist as an ecological protection red line. The calculation of ecological carrying capacity will directly affect the construction scale, product scale, recreational projects and functional positioning of Jiajing Island Recreation Development. Ecological carrying capacity is the minimum value that can be used for an island's recreational space. When the number of tourists in the recreational space reaches saturation, the reception of excess tourists should be prohibited. However, when the number of tourists reached the peak, the scenic area may fall into a low income state It is difficult to maintain operations. According to the preliminary calculation results of the above two calculation methods, it may not be feasible to use the tourist reception volume as a profit point in the development of Jiajing Island Recreation Development, and it must be considered to ensure the profit by increasing the consumption of monomers. Therefore, the development positioning of Jiajing Island must be above the mid-to-high end otherwise it is difficult to ensure the input and output ratio in the later operation process.

\section{Ecological Micro-interference}

Due to the fragile ecological environment of Jiajing Island, the construction of infrastructure is likely to have a negative impact on the ecological environment of Jiajing Island. Therefore, when carrying out infrastructure construction, we must strive for "ecological micro-interference" to minimize the negative impact of infrastructure construction on the ecological environment of Jiajing Island.

\section{1) Construction of ecological micro-interference wharf}

The wharf is very important for the island. It is a way for tourists to go to the island, which is a basic transportation facility. Jiajing Island does not yet have a wharf. When the recreational development of Jiajing Island is carried out, the construction of the wharf in the development process should be prevented from causing damage to the coastline near the construction area. Therefore, Jiajing Island is suitable for the construction of small cruise wharves with little ecological interference. Lightweight driftwood trestles can be used to reduce the impact on nearby coastal beaches and tropical rainforests [17].

\section{2) Construction of ecological micro-interference} municipal infrastructure

Jiajing Island has no municipal infrastructure and cannot meet the needs of tourism development. In the process of recreational development of Jiajing Island, the layout of municipal infrastructure should be scientifically planned, and the infrastructure connection between Jiajing Island and other nearby islands should be strengthened. It is worth noting that the construction of infrastructure is easy to damage the ecological environment of the island. Therefore, during the construction of Jiajing Island's municipal infrastructure, it is necessary to focus on the application of green, environmentally friendly and clean construction technologies, and to build an ecological infrastructure system, striving to micro-interfere with the ecological environment of Jiajing Island, and to meet the ecological sustainable development of Jiajing Island [18].

\section{3) Establish a complete garbage disposal system}

Configure garbage bins that are in harmony with the ecological environment of Jiajing Island, in sufficient quantity and with a reasonable layout, and establish a complete and complete garbage and sewage treatment system on Jiajing Island. Plan a fixed collection point for garbage and conduct strict garbage classification. Manure can be organically treated as fertilizer to nourish the forest, and the recyclable garbage that can be recycled by Jiajing Island is reused by Jiajing Island after professional treatment. The rest of the garbage is transported out of the island every day by professionals at a fixed time for further classification and utilization [19-20].

\section{SUSTAINABLE DEVELOPMENT STRATEGY BASED ON ECONOMIC GOALS}

\section{A. Based on Special Recreational Projects}

\section{1) Focus on professional recreational projects}

The coral reefs around Jiajing Island are rich in coral reef resources, with a wide variety of fishes and good sea bottom clarity, making them a very good diving destination. Although compared with Wuzhizhou Island, Jiajing Island has a more complex diving environment and is not suitable for beginners, but Jiajing Island is known in the industry as "diving into class paradise". Therefore, you can choose to build a professional 
deep diving base, and on this basis, extend the marina, professional sea fishing, photography and other projects. In addition, the 250-meter sandy beach of Jiajing Island has obvious advantages and fine sand, and the beach can change with the seasons. Compared with the positioning of Wuzhizhou Island's main star-rated hotels, entertainment and performance activities, Jiajing Island Recreation Development can focus on projects with professional customer groups such as professional deep diving, recreational recreation, natural experience and yacht fishing. There is no need to set up too many entertainment products and entertainment performances. It mainly promotes professional-level experience, personalized leisure and health care, and long-term return to nature. Especially when there are two freshwater springs on the island, do the above articles. It can be distinguished from other entertainment vacation islands, and it can also fit the development positioning of Jiajing Island.

2) Provide professional supporting facilities for professional recreation projects

For islands that specialize in professional recreational projects, professional and targeted infrastructure construction is crucial. In addition to the basic attribute of ecological microinterference, the design of basic equipment, hotels, entertainment facilities, and ancillary equipment and facilities must also conform to the theme positioning of Jiajing Island. The entry and exit points for professional diving are as close as possible to the resort, and the diving club is set up as the starting point of the resort complex in the southwest corner of the development and construction area. The northeast direction of the island is lined with strange stones, and the bird's eye view of the whole island should be set up. The construction of a resort does not require high-end fashion like a star-rated hotel It needs to be perfectly integrated with the ecological environment around the development and construction area. It is not obtrusive and must have its own style and recognition.

In addition to the harmonious appearance, attention should also be paid to the comfort inside the resort. Good tourist experience comes from refined design. For example, as shown in Fig. 3, the design is a non-air-conditioned gazebo. By arranging the wooden fence plates straight through the adjustment of the air inlet and outlet angles, it can minimize somatosensory problems, increase the air volume, and improve the comfort of tourists. The construction of supporting facilities for recreational projects must not stop at the use of functions. It is necessary to deeply explore the needs of tourists, refine the design, and provide tourists with a more satisfactory experience.

3) Do a good job in free trade and solve the problem of "inside and outside customs"

According to the survey, in the comparison of equivalent duty-free shops in China, taking a brand-name cosmetics as an example, the duty-free shops in Sanya are 3\% higher than Tianjin Outlets, 5\% higher than Qingdao Outlets, and higher than Hong Kong Harbour City $8 \%-15 \%$, high-end watches of the same brand are 10\% -20\% higher than Hong Kong. In 2018 , General Secretary Xi Jinping announced the establishment of the Hainan Free Trade Zone, how to seize the policy dividend, let the policy land, and realize the same price of "inside customs" and "outside customs". The policy has already started a good start. The duty-free sales of single products with highend watches as the mainstay are sufficient to support a side of the industry. And this move is also highly consistent with the national strategic positioning of the "International Tourism Consumption Center".

\section{B. Supported by a Reasonable Spatial Layout}

Reasonable recreation space planning can provide good spatial support for the development of characteristic recreation projects. Island recreation space refers to the physical space within the island that carries recreational activities, and is a space surrounded by mountains, woodlands, buildings, squares, trails, service facilities and other entities [21].

To conduct a reasonable recreational space planning for Jiajing Island, we must first analyze the spatial distribution of Jiajing Island's resources and the delineation of protection areas, and then arrange them reasonably according to the resource distribution of Jiajing Island and the division of protection and development areas Jiajing Island's recreational space. In the previous article, Jiajing Island was divided into protection areas and development and construction areas. For protected areas, a resource-modified development strategy should be adopted to fully protect and display the original natural scenery, and on the basis of not destroying the original ecology, moderately modify the scenery to make the scenery more prominent. For development and construction areas, resource-intensive development strategies can be adopted, and artificially enhanced methods can be adopted to optimize the original scenery and create new landscape spaces. For example, the bedrock shoreline of Jiajing Island presents an excellent landform landscape, which can be used for ornamental purposes and can maintain the stability of the island body, so its positioning is a display of the original ecological scenery. It can be supplemented with a floating plank at a suitable location, such as a glass plank to enhance the ornamental value, and it should not be over-developed. The development and construction areas of Jiajing Island are concentrated in the middle and northern areas with gentle terrain, and the vegetation covered is mostly grass with relatively low protection value. It is suitable for construction and construction, and artificial reinforcement can be used for development and construction, as shown in Fig. 2.

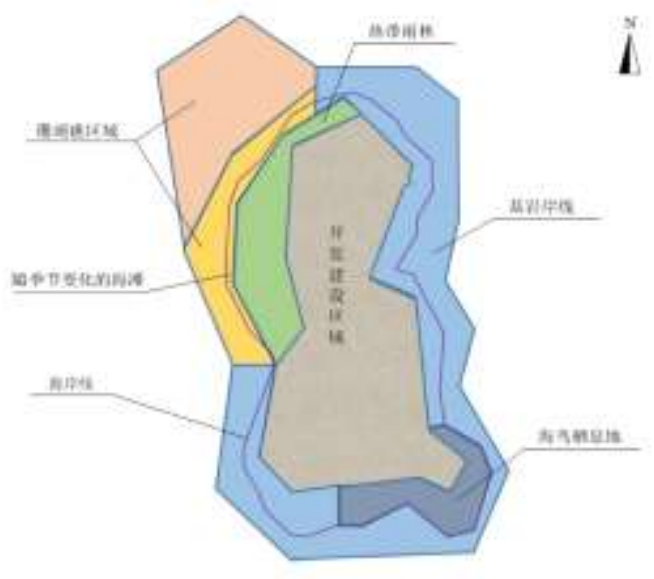

Fig. 2. Jiajing Island resources spatial distribution map 
Because the area of Jiajing Island is relatively small, you can learn from the construction experience of the Maldives Islands, "one island and one village", the resting place is built on the mountain, and the mountain is facing the sun (refer to the room layout of the Mandarin Oriental Hotel in Dadong Seaview Area in Sanya City). From top to bottom, through the whole island, you can intimately touch the fantasy beach, and you can enjoy the beautiful scenery of the island. From the perspective of the docking of recreational projects, there are a large number of coral reefs in the waters around Jiajing Island, and recreational projects for diving viewing can be developed to increase the recreational experience of tourists. There is a $250 \mathrm{~m}$ long beach on the west side of the island, which can change its shape with the seasons. It is also the origin of the "Lingdao" title of Jiajing Island. It can be built as a key product to satisfy the long-term rest tourists' psychology of hunting. From the perspective of ecological protection, it is not advisable to set up too many play items on the beach, but only developed as a viewing product to ensure its original state. There are often seabirds inhabiting and breeding on the southeast side of Jiajing Island. Some viewing platforms can be set up at a certain distance from the habitat for tourists to watch and get close to nature. The distance of the viewing platform must be measured, not only to ensure that tourists can appreciate clearly and enjoyment, but also to ensure that the tourists' viewing behavior will not pose a threat to the breeding and life of seabirds. On the northwest side of Jiajing Island, there are dense tropical rain forests with evergreen seasons, and there are two freshwater springs in the forest. For the protection of ecology, forest areas can be planned to build some walking paths and glass paths for tourists to enjoy the forest scenery It is necessary to ensure the original ecology of the forest, and it is strictly forbidden to install other play facilities and all vehicles to enter. The specific recreation product planning of Jiajing Island is shown in Fig. 3.

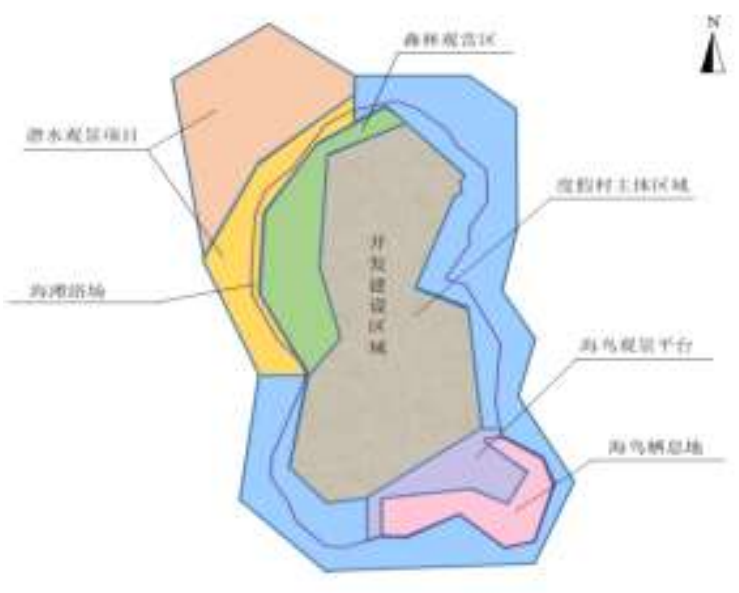

Fig. 3. Schematic diagram of the development and design of Jiajing Island Recreation Space

\section{Competitive with Personalized Attributes}

More and more data show that the development of personalized attributes is an important part of the recreation strategy and a key element of the island's attractiveness. If you want to avoid the problems of geographical location bias, small size, and difficult survival of homogeneous competition, you must create a unique and personalized image of Jiajing Island, and explore its unique style, structure and Different landscapes, construct recreational facilities with Jiajing Island characteristics, and develop a series of recreational products with Jiajing Island unique charm:

1) Unique attributes allow personalized recreation to continue to develop.

If you blindly imitate or even copy the development mode, construction style, and operation mode of other islands, it will make Jiajing Island lose its own characteristics and become one of many indifference islands. Jiajing Island recreation development should follow the principle of uniqueness. Indepth analysis of the characteristics of the natural landscape of Jiajing Island and some special and unique customs and customs, excavating the uniqueness of it, combining the characteristics of the water area and its own beach advantages, to achieve tailor-made islands. On the one hand, it can avoid the siphon effect of successful resorts such as Wuzhizhou Island. On the other hand, it can accumulate the market and attract professional customers.

\section{2) Exquisite in-depth experience allows personalized} virtuous circle.

Jiajing Island has excellent coastline conditions and is a unique recreational resource. It can create a unique recreational image featuring professional deep diving, deeply experience the marine attributes of Jiajing Island and the comfort brought by natural resources, and fully demonstrate the charm of Jiajing Island recreational resources. There are many sea reefs near Jiajing Island. It is suitable for professionals with familiar routes and understanding of the sea area to conduct diving activities in the surroundings. It is this professional existence that makes Jiajing Island full of unknown mystery. Customers have a unique charm.

\section{3) Surf-themed tournament events.}

The winds and waves in the waters around Jiajing Island have affected some tourists to go objectively, but according to their own characteristics, they are even more articles. From the east of Jiajing Island to the west of Shimei Bay to the west of Riyue Bay, the sea water is clear with an average annual temperature of $26.5^{\circ} \mathrm{C}$. Large waves of about 2 meters often occur from October to March of the next year. It has a high wave frequency and long waves, and it is currently the best surfing destination in the country, but it is currently only a few clubs that have been operated independently and have not been planned and formalized. The surfing industry is in urgent need of development and has developed greatly under the unified management of the government.

\section{Powered by Precision Marketing}

Marketing is an indispensable part of human social activities. In this era of information explosion, successful island development is inseparable from successful marketing. The Maldives Islands and Wuzhizhou Island mentioned in Chapter 3 have been very successful in marketing. Although "the wine is not afraid of deep alleys", in the context of today's rapidly developing industry, this sentence can only be 
expressed as the completeness of its own construction. In a highly competitive market environment, if Jiajing Island wants to achieve economic success and long-term development while avoiding the edge of homogeneous competitors, accurate and effective publicity and marketing are essential.

\section{1) Create accurate business cards.}

The business card of Bali is "Forever Summer at $8^{\circ}$ South Latitude", and the business card of New Zealand is " $100 \%$ pure you". These business card slogans clearly and intuitively convey their own recreational characteristics, positioning and services. The domestic "Hospitable Shandong", "Charming Sanya, Romance of the World" can precisely attract the attention of the target group. Therefore, to locate market groups with accurate promotional business cards, we must proceed from the needs of consumer entities and the characteristics of their own development planning, and design simple, suitable for the attributes of Jiajing Island, and accurate, simple, easy to remember and promote promotional slogans. For example, "Mysterious Wonderland (Plus Well), Deep Dive Paradise" with the theme of diving, or "Walking Beach, Long Life with Well" on the theme of movable beaches and other business card slogans to convey the positioning of Jiajing Island, Products and features.

\section{2) Make good use of mainstream media}

In addition to the publicity slogan, direct or indirect publicity through mainstream media is also a direct and effective method. Film and television works often interact with each other to complete the scene. Film and television works can show the beauty of the scenic area. The beautiful scenery of the scenic area can also help the final effect of the film and television works. Fan, the urge to reproduce the film and television plot [22]. Wuzhizhou Island, as the shooting venue of "Private Customization", has provided great help for its promotion and marketing and opening its popularity. The popularity of Bali is also related to the high frequency of its appearance in film and television works. As the shooting location of "You Are the One 2", Jiajing Island has allowed viewers to appreciate the beautiful scenery on the big screen many years ago. You can continue to use this approach after development, which is very helpful for opening popularity.

3) “Internet +" marketing method.

As far as the current marketing platform is concerned, the proportion of the Internet is very large. Jiajing Island Marketing must closely follow the trend of the times, closely integrate its own recreational development with the development of the Internet, and actively publish its own information on the Internet to enhance its popularity. At the same time, we must pay attention to the new media sector, work closely with various media platforms, and publish soft texts with a marketing nature through various APPs and public accounts to promote our recreational products. In addition, we must cooperate with Ctrip, Tuniu, Meituan, Dianping, and other emerging social media sites and travel platforms, and use a professional network operation team to enhance visibility. With the continuous progress of society, there will be more marketing innovations in the future. The Internet will always be an auxiliary means, not as a main tool. Therefore, in the marketing aspect, how to use the hot spots linked to the society to carry out positive information dissemination is the most important solution. Any marketing methods and methods should keep pace with the times and comply with relevant legal policies and business standards. Only in this way can we truly achieve coordinated and sustainable development.

\section{Sustainable DeVElopMent STRATEGy BASED ON SOCIAL COORDINATION}

\section{A. Based on the Visitor Experience}

On the premise of protecting the ecological environment and respecting the rules of nature, Jiajing Island Recreation Development should take the experience of tourists as the foundation. The strict protection of the ecological environment during the development process is to create a recreational environment of excellent quality and to ensure the sustainable development of Jiajing Island. However, tourists are the experiencers of Jiajing Island's recreational environment and the main source of economic resources after the operation of Jiajing Island. Therefore, the needs of tourists must not be ignored. However, taking the tourist experience as the fundamental means not only considering the needs of tourists, but ignoring everything else, but attaching importance to the harmonious unity of people, nature, and society. This is its more important meaning. First of all, while protecting the ecological environment, Jiajing Island should take the experience of tourists as the focal point of planning, targeted design and reasonable development of island recreational spaces, and develop products that are close to nature and integrated into natural recreation for the target tourist groups. Serve the needs of tourists. Secondly, according to actual needs, some existing landscapes can be optimized to a certain extent to make it more in line with the aesthetics of tourists, and more practical and comfortable, and improve the satisfaction of tourists. Finally, it is necessary to rationally plan the delicate link between the visitor's stay space and the ecological protection space, minimize the impact of tourist recreational activities on the fragile ecological environment, complete the harmonious coexistence of man and nature, and promote the coordinated development of man and society.

\section{B. Strengthen Linkage and Integration Development with Surrounding Scenic Spots}

In the development of future recreational projects, environmental protection is paramount. In order to protect the natural environment of Jiajing Island, ensure its natural resource advantages, ensure the harmonious coexistence of man and nature, coordinate the development of ecology and industry, and maintain the social stability of Jiajing Island, it is necessary to strengthen the planning of recreational development of Jiajing Island The integration with the surrounding scenic spots is not only the industrial integration, but also the social integration.

First of all, for the recreational development of Jiajing Island, it is necessary to abandon all modern industries and cut off the pollution caused by the industry from the roots. The area of Jiajing Island is limited, and it is impossible to balance the protection of the ecological environment and the construction of a complete industrial structure. Therefore, it is necessary to strengthen the industrial integration of Jiajing 
Island, Shimei Bay Scenic Spot, and even Hainan Island, so that Jiajing Island becomes Shimei Bay Scenic Spot. Even part of the Hainan International Tourism Island industrial chain. Secondly, to strengthen its social integration with the surrounding scenic spots, the most direct way is to ensure the convenient transportation of Jiajing Island and the surrounding scenic spots, and vigorously develop external transportation and exchanges. Under the condition of not damaging the ecological environment, realize the freedom of tourists to travel between Jiajing Island and the surrounding scenic spots. Finally, according to the seasonal characteristics of tourism activities, the ecological environment of Jiajing Island is regularly repaired. At the time of replanting and maintenance of the fragile ecological resources of tropical rain forests, on the other hand, we can follow the practice of Wuzhizhou Island, build tropical marine pastures, and repair the marine ecology of Jiajing Island. In short, we must do our best to maintain the harmony between people and nature on Jiajing Island, and promote the coordinated development of the ecological environment and society.

\section{Guaranteed by the Government's Overall Planning}

Xiamen "Tour Island Tour" is a typical example of government-led and overall planning. The role of the government in the development of the Maldives Islands cannot be ignored. Therefore, in order to guarantee the sustainable development of the society of Jiajing Island, the government should take the initiative to make overall plans, manage and implement, mainly divided into the following two aspects:

1) The government should use Tourism + as a platform to ensure the possibility of the smooth development of recreational development of Jiajing Island, and actively recruit students and attract investment.

Without investors, there will be no capital for recreational development of Jiajing Island. Since there are certain investment risks in the recreational development of Jiajing Island, it is even more necessary for the government to help attract investment. At present, the central government's policy is open enough, and the detailed landing details in the province are still on the way. Attracting investors to invest in Hainan, the benefits of this approach not only can be enjoyed by Jiajing Island, but also benefit other developed or undeveloped uninhabited islands. It is also very helpful for the construction of Hainan International Tourism Consumer Center of. Secondly, the government can carry out a comprehensive tourism promotion meeting for Jiajing Island, attracting foreign investment, and the resource endowment of Jiajing Island is outstanding, and it can also increase the weight for the investment of recreational development of Jiajing Island.

2) Strictly approve and standardize the management system to ensure the sustainable development of Jiajing Island

Maldives islands have to undergo a strict approval process before they are developed, and Hainan Province also has its own non-resident island development approval process. First of all, in the approval process, government departments should strictly check to ensure the feasibility of recreational development of Jiajing Island. Secondly, drawing on the Maldives' development experience, "one island, one enterprise", overall development, only one enterprise in Jiajing Island develops and operates. While avoiding multiple companies competing for power and profit, the implementation of Jiajingdao 's management responsibilities on the enterprise is conducive to the overall management, accountability and social stability of Jiajingdao after it is put into operation. Finally, the government can regulate the development and operation of enterprises by formulating relevant systems, regulations, and related laws and regulations to ensure that they will not make measures that endanger the ecological environment and social stability of Jiajing Island, and protect the ecology, economy, and society of Jiajing Island Sustainable development.

\section{CONCLUSION}

Located in Hainan Province, Jiajing Island is relatively rich in tourism resources and has a few constraints. The current policy trends and market orientation provide many potential opportunities for the development of Jiajing Island, but at the same time, the existing ecological environment of Jiajing Island is relatively fragile and belongs to its own disadvantages. The current market competition is fierce. It also brought a lot of pressure. Therefore, in the process of recreational development of Jiajing Island, it is necessary to take ecological protection as a guide, based on unique recreational projects, based on the experience of tourists, and develop rationally, not blindly overdeveloping. First, we must pay attention to protecting the original ecological environment system of Jiajing Island, and cannot touch the ecological protection red line of Jiajing Island; secondly, in the development process, we must adapt to local conditions and the island's construction industry to highlight the unique characteristics of Jiajing Island Finally, it is necessary to strengthen industrial integration and social integration with the surrounding scenic spots. At the same time, the government should properly intervene, make overall plans, maintain the social stability of Jiajing Island, and finally achieve the ecological, economic, and social sustainable development of Jiajing Island recreational development.

\section{ACKNOWLEDGMENT}

This research was financially supported by the Sanya Planning Projects of Philosophy and Social Sciences (No.SYSK2019-07); 2019 Education and Teaching Reform Project of Hainan Tropical Ocean University (No.RHYJG2019-17).

\section{REFERENCES}

[1] Y.M. Wang, W.J. Wu, L. Qian, etc., "Eco-civilization-oriented tourism development mode transformation-Based on the case of Chongming Island," Tourism Science, Vol.24, No.04, 2010, pp.1-11+25.(In Chinese)

[2] C.H. Fang, "Theoretical and technical framework of single island protection and utilization planning," Marine Development and Management, Vol.33, No.09, 2016, pp.15-19.(In Chinese)

[3] K. Zhang, C. Shen, Q. Gao, etc.,"Ultra Wideband Positioning Technology for Accident Ships under Adverse Sea Condition," Journal of Coastal Research, Vol.83, No.sp1, 2018, pp. 902-907. 
[4] Y.D. Han, C.H. Chen, Y.H. Yu, etc., "On the protection and utilization planning of uninhabited islands — Taking Wanning Jiajing Island as an example," Marine Information, No.04, 2016, pp.60-64.(In Chinese)

[5] Y.M. Zhang, "Research on Xiamen 's uninhabited island development planning based on ecotourism," CN: Huaqiao University, 2015.(In Chinese)

[6] K. Zhang, C. Shen, M.X. Huang, etc.,"'Interrupt Protection Control of Anti-Interference Nodes in Network Based on Band Sampling Decision Filter Modulation," Cluster Computing - The Journal of Networks Software Tools and Applications, Vol.22, No.SI3, 2019, pp.7569-7576.

[7] Q. Li, "Research on the Transformation and Upgrading of Sanya West Island Tourism Industry," CN: Hainan Institute of Tropical Oceanography, 2018.(In Chinese)

[8] H.H. Yan, "Research on the Ecological Environment Evolution and Evaluation of Wuzhizhou Island Marine Ranch Tourism Area in Sanya" CN: Hainan University, 2017.(In Chinese)

[9] H. Hong, Y.X. Hu, S. Hu, "Development Status and Innovation Development of Unmanned Island in Zhoushan," China Population, Resources and Environment, No.S1, 2010, PP. 439-442.(In Chinese)

[10] K. Zhang, C. Shen, H.W. Li, etc., "Direction of Arrival Estimation and Robust Adaptive Beamforming With Unfolded Augmented Coprime Array," IEEE Access, Vol.8, 2020, pp. 22314-22323.

[11] Y.G. Liu, "Liaoning Island Economy and Development and Utilization of Unmanned Island (Part 2)," Liaoning Economy, No.02, 2013, pp. 7579.(In Chinese)

[12] C. Shen, C.X. Wang, K. Zhang, etc.,"A Time Difference of Arrival/Angle of Arrival Fusion Algorithm with Steepest Descent Algorithm for Indoor Non-Line-of-Sight Locationing," International Journal of Distributed Sensor Networks, Vol.15, No.6, 2019, pp.1-8.
[13] K. Zhang, C. Shen, Q. Gao, etc.,"Precise Positioning System of Ship Interior Based on UBW Ultra Wideband Technology," Journal of Coastal Research, Vol.83, No.sp1, 2018, pp. 908-912.

[14] Q.B. Wang, "The development, protection and management of unmanned islands in South Korea," Ocean Development and Management, No.10, 2015, pp. 30-34.(In Chinese)

[15] K. Zhang, C. Shen, H.F. Wang, etc.,’Design Of Ship Medical Rescue Communication System Based On Mimo Precise Positioning," Indian Journal Of Pharmaceutical Sciences, Vol.80, No.S1, 2018, pp. 42-43.

[16] M. Ren, J. Dai, "Suitable Spatial Planning and Design in Tourism Development of Unmanned Island," Economic Research Guide, No.26, 2017, pp. 121-122.(In Chinese)

[17] Y.S. Miao, "Zhejiang Province Research on the Development and Management of Unmanned Islands," Marine Information, No.04, 1999, pp. 23.(In Chinese)

[18] K. Zhang, C. Shen, H.W. Li, etc., "Design of Robot System for Hospital Infection Prevention and Control Based on UWB Technology," Basic \& Clinical Pharmacology \& Toxicology, Vol.126, 2020, pp. 68-69.

[19] Y.N. Yang,"Dynamic monitoring of the development and utilization of uninhabited islands in Liaoning based on remote sensing," Technology Innovation and Application, No.20, 2019, pp. 65-66.(In Chinese)

[20] W. Fang,"Island, the Pearl Pnlaid on the Blue Land," Ocean and Fishery, No.01, 2019, pp. 4-5.(In Chinese)

[21] K. Zhang, C. Shen, Q. Zhou, etc.,"A Combined GPS UWB and MARG Locationing Algorithm for Indoor and Outdoor Mixed Scenario," Cluster Computing - The Journal of Networks Software Tools and Applications, Vol.22, No.SI3, 2019, pp.5965-5974.

[22] J. Liao,'Zhuhai Delta Island, Public Welfare Development of Ecological Tourism," Ocean and Fishery, No.01, 2019, pp. 20-23.(In Chinese) 